\title{
A Power factor corrector using interleaved boost fuzzy-logic converter: design, analysis, and implementation
}

\author{
Mentari Putri Jati ${ }^{1, *}$ \\ ${ }^{1}$ Universitas Negeri Yogyakarta, Jl. Colombo No.1 Yogyakarta 55281, Indonesia \\ E-mail: mentariputrijati@uny.ac.id* \\ * Corresponding Author
}

\begin{tabular}{|c|c|}
\hline ABSTRACT & ARTICLE INFO \\
\hline $\begin{array}{l}\text { The technology for developing power factor correction is increasingly being discussed } \\
\text { because of the increasing number of nonlinear loads that exist. This is related to power } \\
\text { quality which can affect load system performance because nonlinear loads cause low } \\
\text { power factor and the appearance of harmonic currents. However, it takes a power } \\
\text { factor corrector converter that has a simple construction and reliable performance. } \\
\text { Interleaved Boost Converter is often applied as a power factor corrector converter } \\
\text { because it has these advantages. Combined with a fuzzy controller it is a proposed } \\
\text { system to achieve a near unity power factor. The discontinuous Conduction Mode } \\
\text { (DCM) technique is used because it has an efficient inductor design. The results of the } \\
\text { proposed system design were proven by simulation and hardware implementation } \\
\text { which resulted in significant power factor improvements. }\end{array}$ & $\begin{array}{r}\text { Keywords } \\
\text { Power Factor Corrector } \\
\text { Interleaved Boost } \\
\text { Converter } \\
\text { Fuzzy Logic }\end{array}$ \\
\hline \multicolumn{2}{|l|}{ This is an open-access article under the CC-BY-SA license. } \\
\hline (cc) (i) () & \\
\hline
\end{tabular}

\section{Introduction}

Latterly, concerning power quality, many problems have received the attention of researchers, including Power Factor Corrector (PFC) [1]. This is proportional to the increase in equipment that uses DC sources which increases the use of nonlinear devices in the form of rectifiers. Most power electronics devices use full-wave rectifiers, which are nonlinear in nature. Nonlinear loads with power factors adversely affect the system power factor.

The appearance of nonlinear devices results in low power factor operation and high harmonic distortion [2]. The IEC 61000-3-2 Harmonics Regulation defines the power factor in several applications, such as portable tools (class B), lighting equipment (class C), computers (class D), etc. [3]. Harmonics can also reduce the quality of the electrical power system which can cause negative impacts on other equipment in a grid.

Power factor improvement is required in this case to meet harmonic standards, longer device lifetime, and proper operation of other devices in the system. Other advantages of PFC include increased electrical system capacity [4], diminished power losses and switching losses in the distribution system [5], increased system efficiency [6], decreased voltage drops that cause overheating [7], and premature failure in the case of motor loads and other inductive equipment [8]. Active-type power factor correction circuits typically use a power supply counting to reduce 
the harmonics of the alternating input current (AC) and regulate the unidirectional (DC) output voltage. The converter topology increases the voltage (boost) continues to be used in various applications AC to DC and another way. The boost type converter is the most popular series of active power factor improvements in the electric vehicle battery charger [9], electric aircraft [10], and HVAC application [11].

According to the inductor current waveform, the operating modes of the boost power factor correction converter are grouped into continuous current conduction mode (CCM), critical current conduction mode (CRM), and discontinuous current conduction mode (DCM) [12]. CRM and DCM PFC boost converters have advantages such as zero current when the switch is connected and no diode reverse current. The switching frequency of the CRM boost power factor improvement converter varies. Meanwhile, the inductor and EMI filter design are more difficult. In addition, the DCM boost power factor correction converter is operated at a constant switching frequency. To achieve a power factor close to unity with a simple circuit composition, conventional boost converters with interrupted conduction mode operation are widely used by the industry [13].

In terms of control, proportional-integral (PI) or conventional control is a good solution but has limited performance when used in non-linear induction motor systems. Meanwhile, fuzzy logic controllers have the advantage of controlling systems with high nonlinearity. Fuzzy logic has been widely used as a speed control system because of its reliability, efficiency, and simple algorithm [14].

IBC design with CCM requires a larger inductor design than DCM [15]. So with these considerations, the proposed system uses the DCM technique. The use of an interleaved boost converter (IBC) has led to the flow of parallel current through the inductor which results in the use of a lower loading inductor and capacitor. By operating the IBC at a 50\% voltage cycle ratio, the voltage and ripple current have been greatly diminished.

This paper contributes to the design, analysis, and implementation of interleaved boost converter (IBC) as a Power Factor Corrector (PFC) using a fuzzy controller which affects the value of the harmonic system. Hardware systems built on a small scale with varying resistive loads are lamps. The discontinuous current mode (DCM) interleaved boost converter technique is applied to the system to produce a system power factor close to unity. Details of the converter design are also explained for the real hardware implementation design. The improvement in the power factor was proven in simulation and experimental which matched the results.

\section{Converter Design and System Controller}

\subsection{Interleaved Boost Converter (IBC)}

The proposed converter is shown in Fig. 1 that the interleaved boost converter (IBC) is two parallel boost converter circuits. The circuit with inductor $L_{1}$, diode $D_{1}$, switch $S_{1}$ forms a boost circuit, and inductor $L_{2}$, diode $D_{2}$, switch $S_{2}$ from the parallel boost circuit. Capacitor $C$ is used to maintain the output ripple voltage and $R$ is the load resistance. 


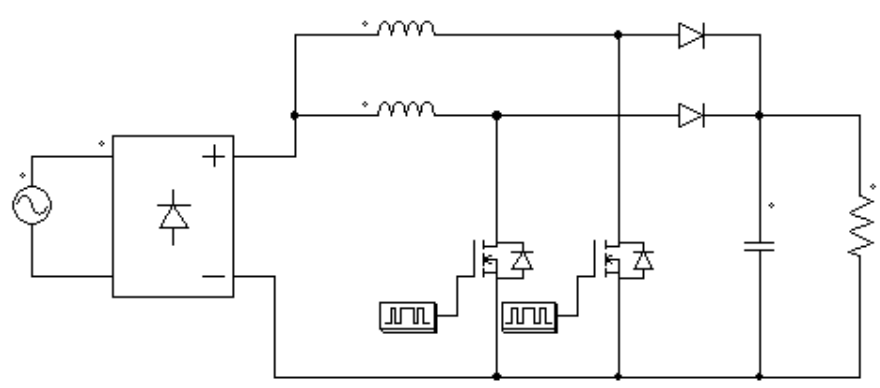

Fig. 1. Interleaved Boost Converter (IBC) topology

\subsection{Discontinuous Conduction Mode (DCM)}

Conventional boost converters have been widely used for active power factor improvement circuits due to their simple and reliable topology. However, this new circuit uses a dual boost converter connected in parallel. Inductor $L_{1}$ and switch $S_{1}$ are used as a power factor improvement circuit while inductor $L_{2}$ and switch $S_{2}$ replace the active filters to improve the quality of input currents containing harmonics. Active filters also reduce switching losses in the circuit. IBC circuit analysis based on such a single boost converter in Discontinuous Conduction Mode (DCM). The DCM IBC operation has three different types such as:

- Switch on and diode reverse bias

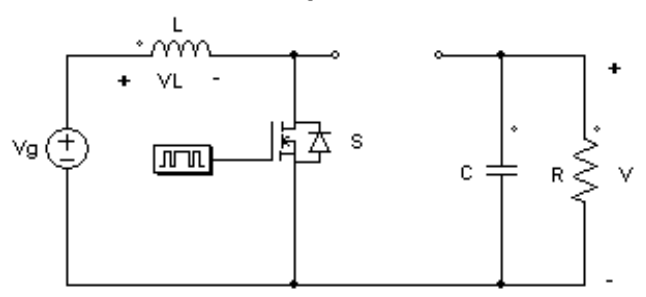

Fig. 2. DCM operation during $0<t<D_{1} T_{s}$.

- Switch off and diode forward bias

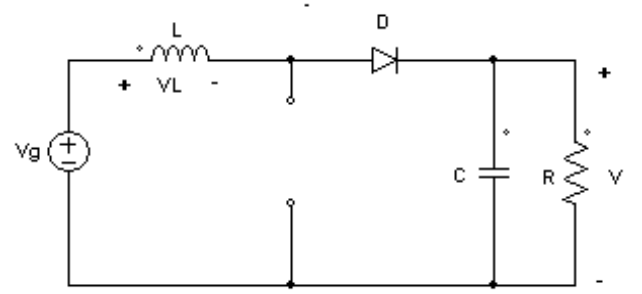

Fig. 3. DCM operation during $D_{1} T_{s}<t<\left(D_{1}+D_{2}\right) T_{s}$.

- Switch off and diode reverse bias

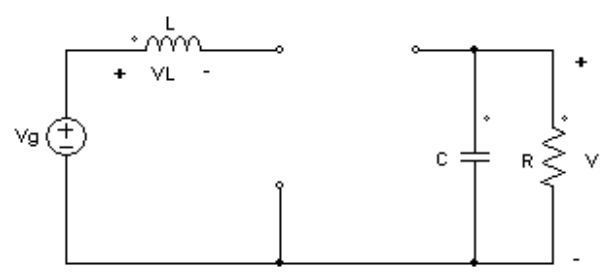

Fig. 4. DCM operation durung $\left(D_{1}+D_{2}\right) T_{s}<t<T_{s}$. 
The mathematical equation of DCM IBC operation is shown below [16]:

$$
\begin{aligned}
& V_{L}(t)=V_{g} \\
& i_{C}(t)=\frac{-V(t)}{R} \\
& V_{L}(t)=V_{g}-V(t) \\
& i(t)=i_{C}(t)+\frac{V(t)}{R} \\
& i_{C}(t)=i(t)-\frac{V(t)}{R} \\
& V_{L}(t)=0 \\
& i(t)=0 \\
& i_{C}(t)=\frac{-V(t)}{R}
\end{aligned}
$$

Where, $V_{L}(t)=$ inductor voltage; $V_{g}=$ supply voltage; $V(t)=$ load voltage; $i(t)=$ inductor current; $i_{C}(t)=$ capacitor current; $R=$ load resistance.

Equations (1) and (2) are obtained from the IBC circuit with a switch connected and a forwardbiased diode that shows in Fig. 2. While (3) - (5) operate when the switch is connected and the diode is forward biased that shows in Fig. 3. And finally, (6) - (8) when the switch is not connected and the diode is reverse biased that shows in Fig. 4. Equations (1), (3), and (6) are used to draw the inductor voltage wave as shown in Fig. 5. With a balanced voltage per second, this wave does not contain a DC component when the converter operates in a stable condition. The inductor current graph based on (4) and (7) can be illustrated in Fig. 6a which is followed by the diode current graph in Fig. $6 b$.

The correlation of the proposed IBC system can function as a power factor corrector which is explained in detail in [16] where the power factor improvement series, input resistance $r_{s}(t)$ is calculated from supply voltage $V_{g}$ and supply current $i_{s}(t)$ every one switching period. The equation for the input resistance $r_{S}(t)$ is stated below:

$$
r_{S}(t)=\frac{2 L}{D^{2} T_{S}}
$$

Where, $r_{S}(t)=$ input resistance; $D=$ duty cycle; $T_{S}=$ time sampling; $L=$ inductor.

Since the values of $L, D$ and $T$ do not change, the input resistance is constant. Based on (9) with a sinusoidal input voltage and constant $r_{s}(t)$ input resistance, the $i_{s}(t)$ current follows the sinusoidal input waveform so that the load is resistive which has a power factor of close to unity.

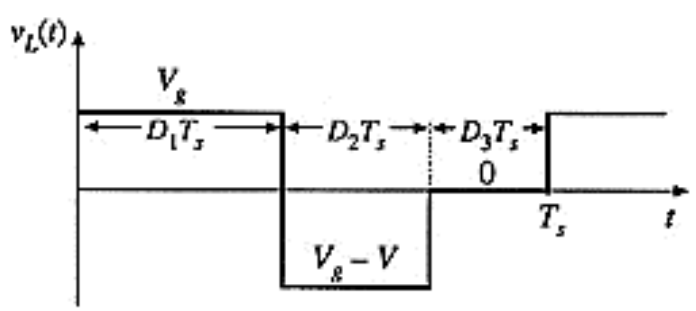

Fig. 5. The waveform of inductor voltage $V_{L}(t)$ Discontinuous Conduction Mode (DCM) boost converter 
(a)

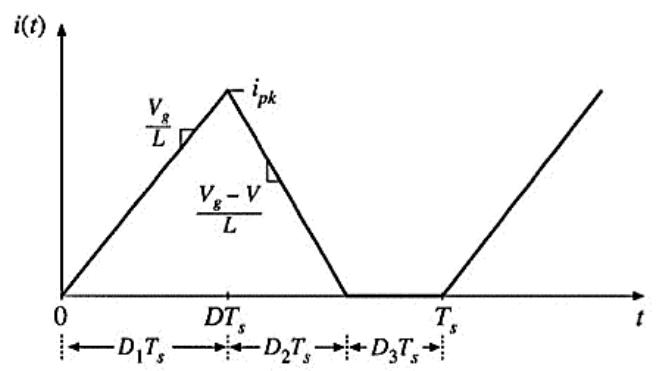

(b)

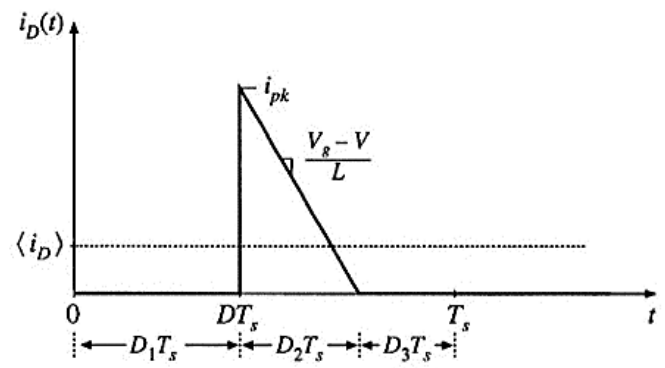

Fig. 6. The waveform of converter current (a) inductor current $i(t)$ (b) diode current $i_{D}(t)$.

\subsection{Inductor Design}

The main component of the converter is the inductor design because it will affect the input and output currents. The power factor correction converter is used according to the following conditions:

- Input voltage $V_{S}$

$: 28.82$ volt

- Output voltage $V_{o}$ : 48 volts

- Efficiency $\eta$ $: 90 \%$

- Switching frequency $f_{s}: 40 \mathrm{kHz}$

So, the design of the converter inductor begins with the calculation of time sampling $T s$, duty cycle $D$, and load resistance $R$ as below:

$$
\begin{aligned}
& T S=\frac{1}{f_{s}}=\frac{1}{40 \mathrm{k}}=25 \mu \mathrm{s} \\
& V_{o}=\frac{V_{S}}{1-D} \\
& 1-D=\frac{V_{S}}{V_{o}} \\
& 1-D=\frac{28.82}{48} \\
& D=0.4 \\
& R=\frac{P_{o}}{\left(I_{o}\right)^{2}} \\
& R=\frac{48}{(1.25)^{2}}=38.4 \Omega \\
& L_{\min }=\frac{D(1-D)^{2} R}{2 f} \\
& L_{\min }=\frac{0.4 \times(1-0.4)^{2} \times 38.4}{2 \times 40000} \\
& L_{\min }=69.1487 \mu \mathrm{H}
\end{aligned}
$$


For IBC DCM operation $\rightarrow \mathrm{L} \leq \mathrm{L}_{\text {min }}$

$$
\begin{aligned}
L & =\frac{1}{2} \times 69.1487 \mu H \\
L & =34.57 \mu H
\end{aligned}
$$

Where, $T_{S}=$ time sampling; $f_{S}=$ switching frequency; $V_{o}=$ output voltage; $V_{S}=$ input voltage; $D=$ duty cycle; $R=$ load resistance; $L_{\min }=$ minimum inductor; $L=$ inductor.

The proposed system has an IBC output current value $I_{o}=1.25 \mathrm{~A}$, so the calculation of the output capacitor $C$ is as below:

$$
\begin{aligned}
& \mathrm{I}_{\text {Dpeak }}=\frac{\mathrm{Io}}{\mathrm{D}}=\frac{1.25}{0.4}=3.125 A \\
& \mathrm{I}_{\text {Drms }}=\mathrm{I}_{\text {Dpeak }} x \sqrt{\mathrm{D}}=3.125 x \sqrt{0.4}=1.9764 A \\
& \mathrm{I}_{\mathrm{Crms}}=\sqrt{\left(\mathrm{I}_{\mathrm{Drms}}\right)^{2}-\left(\mathrm{I}_{\mathrm{o}}\right)^{2}} \\
& \mathrm{I}_{\mathrm{Crms}}=\sqrt{(1.9764)^{2}-(1.25)^{2}} \\
& \mathrm{I}_{\mathrm{Crms}}=1.53 \mathrm{~A} \\
& \mathrm{C}=\frac{\mathrm{I}_{\mathrm{Crms}} \mathrm{D} T_{S}}{\Delta \mathrm{Vo}} \\
& \mathrm{C}=\frac{1.53 \times 0.4 \times 25 \mu}{0.048}=318.75 \mu F \\
& \quad \text { Where, } I_{D p e a k}=\text { diode peak current; } I_{\text {Drms }}=\text { diode rms current; } I_{C r m s}=\text { capacitor rms current; } \\
& C=\text { output capacitor; } D=\text { duty cycle; } T_{S}=\text { time sampling; } \Delta V_{o}=\text { permitted output voltage differences } \\
& (0.1 \% \text { from output voltage })
\end{aligned}
$$

\subsection{Fuzzy Logic System Control}

Fuzzy logic controllers are an alternative to modern control systems that do not require a mathematical model of a system. This controller is still effective because it has a stable system response. IBC requires a controller to stabilize the output voltage. The designer controller in closed-loop simulation with input voltage from the rectifier. The closed-loop simulation circuit of the IBC is shown in Fig. 7. Using the triangular membership function in the Mamdani fuzzy model, we can relate each variable, for example, errors and the change of error or delta errors in the rules to provide output.

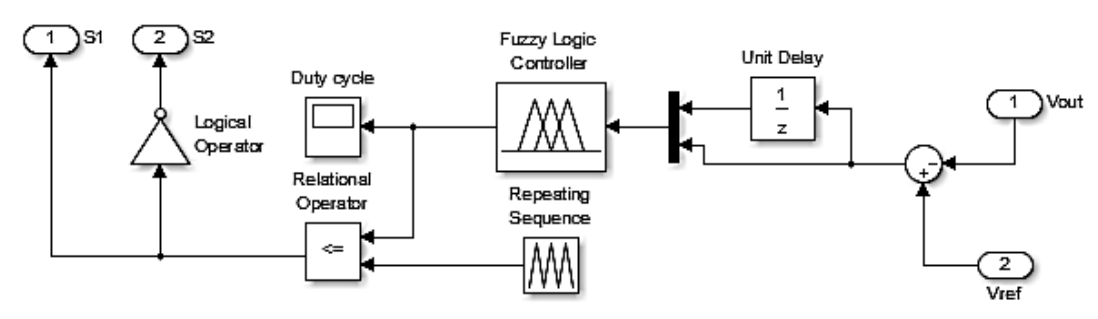

Fig. 7. Design of fuzzy controller of PFC IBC in Matlab Simulink

The fuzzy design uses the Mamdani type with two inputs, error and delta error, and one output that drives the IBC switching mosfet. Both input and output use the form of a triangular membership function. Meanwhile, the fuzzy rules will provide a variable output value change. The FIS editor is used to enter fuzzy variables. The overall coordination of the FIS editor, membership function editor, and rule editor fuzzy logic controller is shown in Fig. 8. 


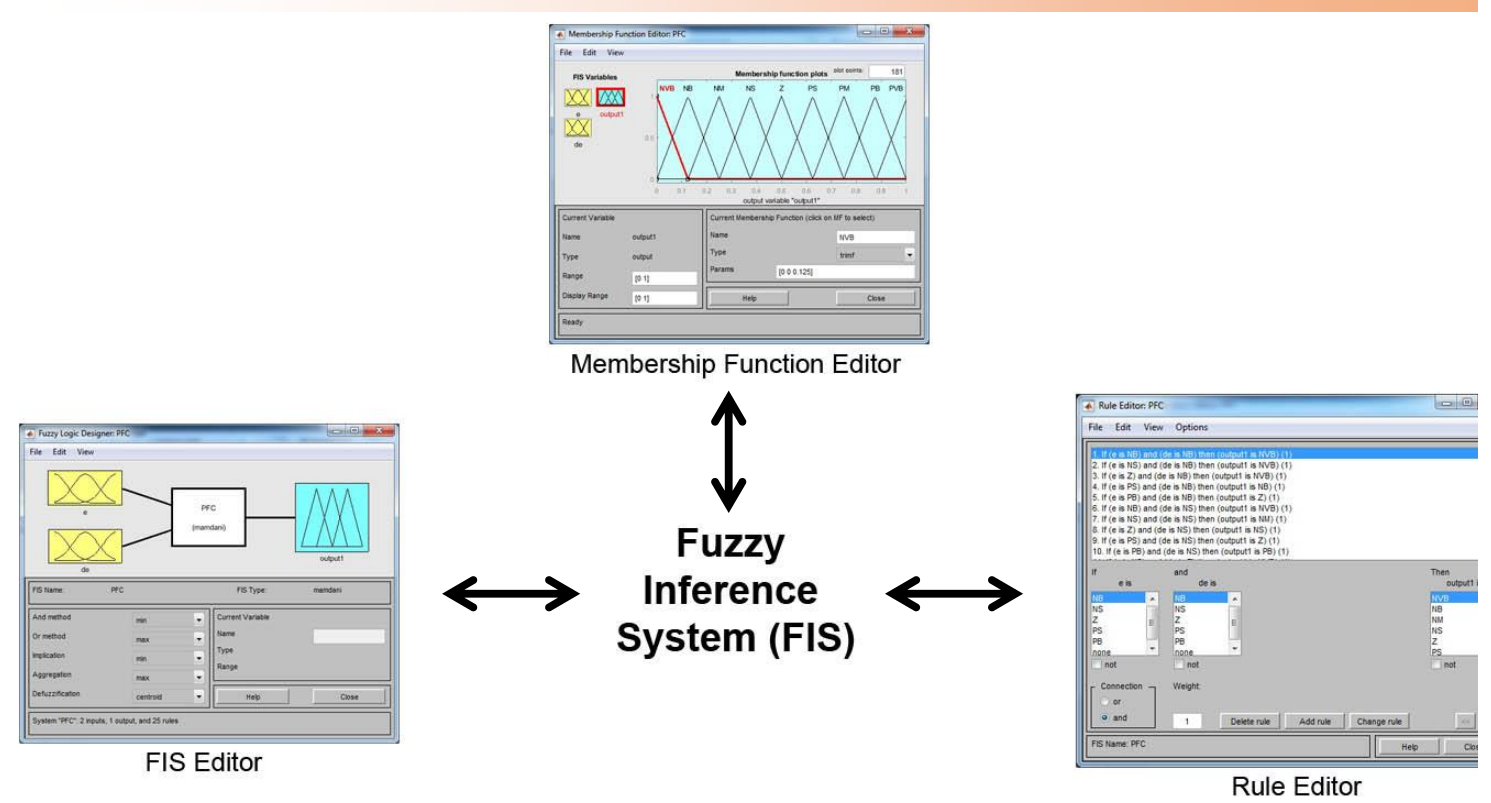

Fig. 8. A whole Fuzzy Inference System (FIS) PFC IBC

\section{Simulation and Experimental Results}

Based on the block diagram system design in Fig. 9, the proposed system parameters are 18.94 volt input voltage and 48 volt output voltage Interleaved Boost Converter (IBC) for designing the converter as a PFC and voltage regulator. The type of converter switch is IRFP460 Mosfet. The simulation results are carried out in the Matlab Simulink software with the same parameters as the hardware design. The simulation and hardware implementation were carried out in two stages, namely testing the system without and with the power factor improvement converter.

The experiment uses a variation of the resistive load in the form of a 220 volt $100 \mathrm{~W}$ lamp installed in parallel. There are three types of load variations based on the number, namely 3,4 , and 5 parallel lamps of $100 \mathrm{~W}$. With a resistive load in parallel, each test with a load variation produces different input and output currents.

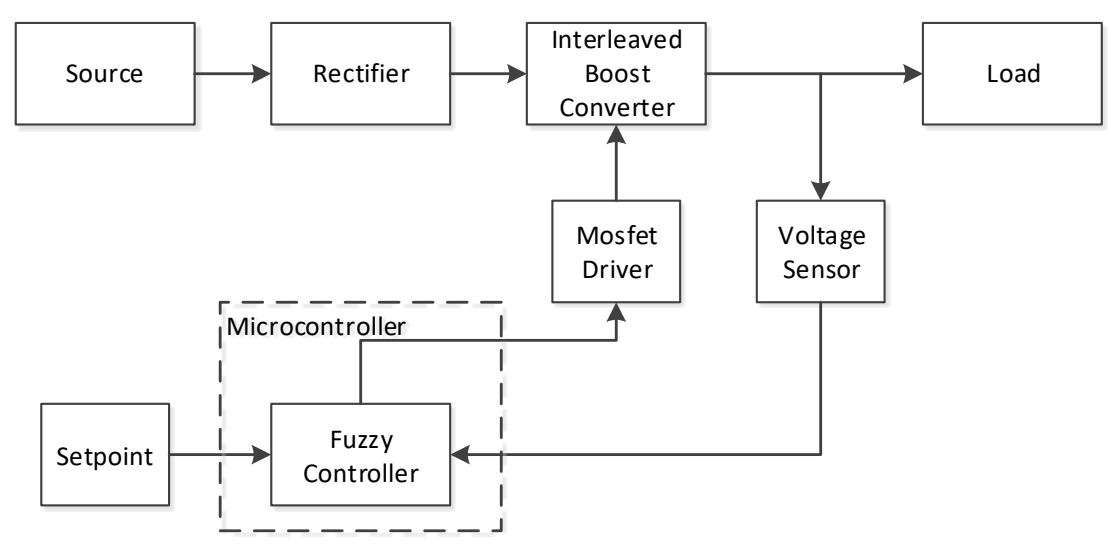

Fig. 9. System diagram block of PFC IBC. 


\subsection{Matlab Simulation}

The Matlab simulation uses the same system parameters as the experiment to compare the results of both results. The block diagram of the Matlab Simulink simulation is shown in Fig. 10. In a DC power supply system with a large filter capacitor, it produces a pure DC output voltage without a ripple but has a phase-shifted of input voltage and input current wave.

The input current wave is not sinusoidal shaped due to the fundamental value mixed with the currents from the effect of charging and discharging the capacitor. The difference in voltage and current waveform causes the input-side power factor not according to the applicable standard $(<85 \%)$ as shown in Fig. 11. The input voltage waveform in the top graph Fig. 11 is sinusoidal and the bottom graph is distorted input current.

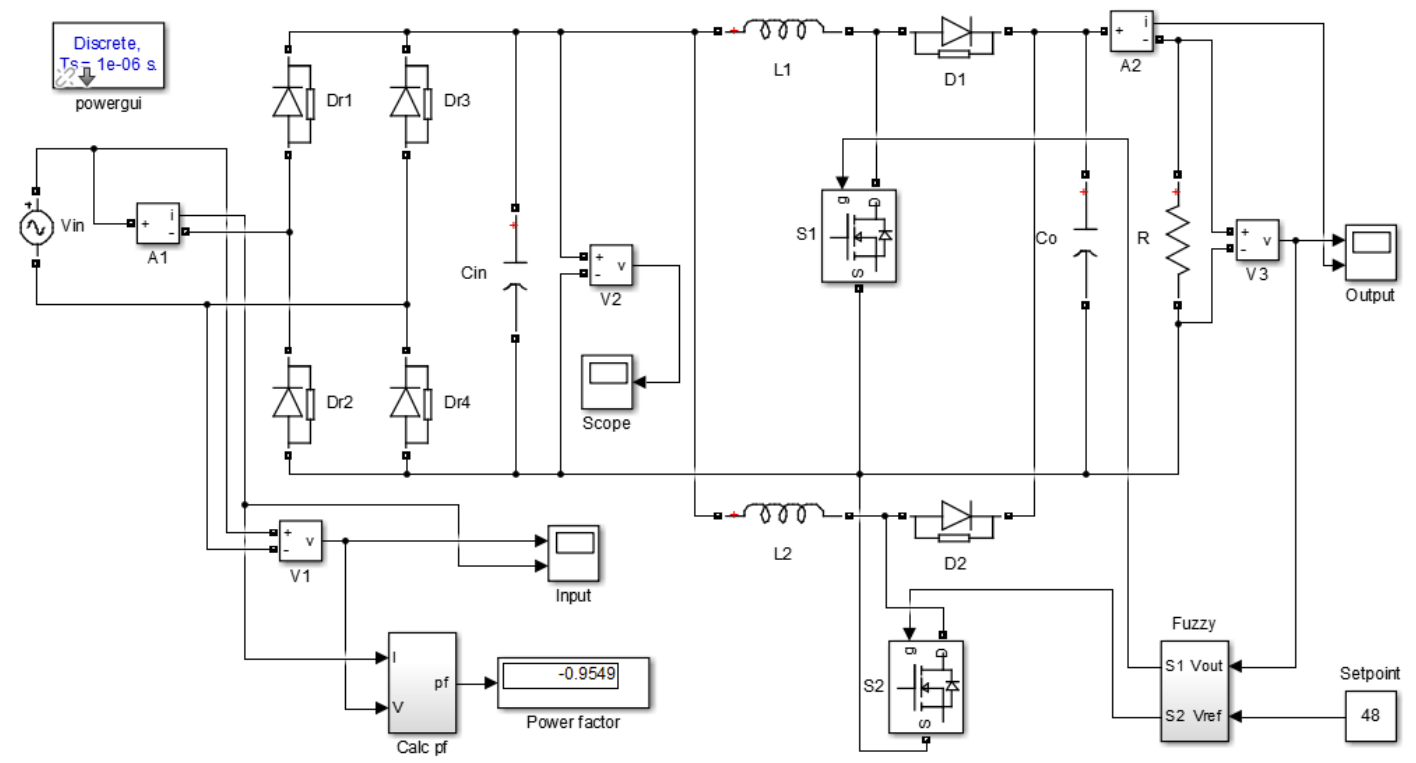

Fig. 10. System simulation of PFC IBC in Matlab Simulink.

The use of large output side filter capacitors can be eliminated by a power factor corrector converter such as an IBC. Therefore, systems using IBC do not require large filter capacitors to produce the input voltage and current at the same phase. The current wave in the system with IBC is shown in the Matlab simulation shown in Fig. 12. The top graph is the input voltage and the bottom one is input current. Both voltage and current have the same phase with more spikes in the current waveform. It is caused by converter switching.

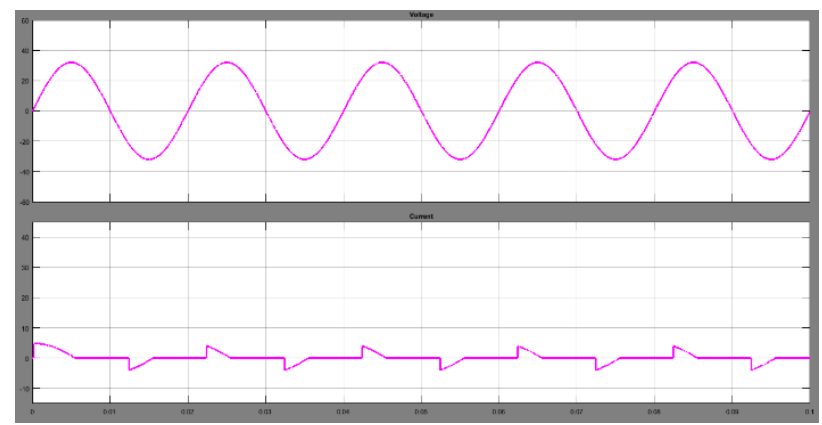

Fig. 11. Input voltage vs input current without PFC IBC. 


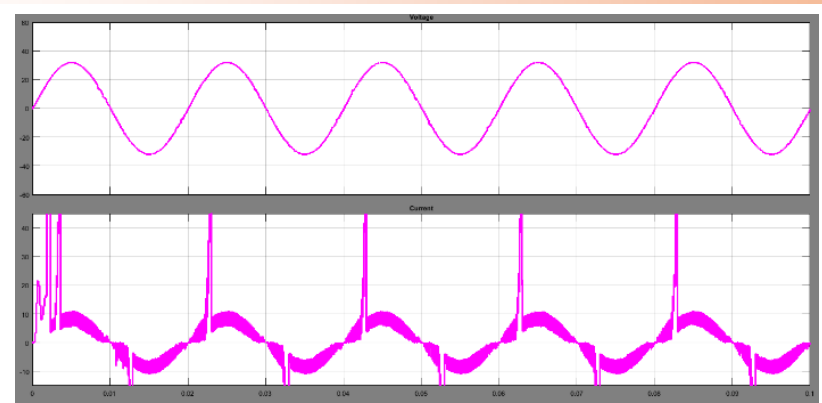

Fig. 12. Input voltage vs input current with PFC IBC

\subsection{Experimental Result}

To evaluate and prove the superiority of the power factor improvement converter in this application, implementation hardware has been built. The converter circuit is determined based on the design described in the previous section and the prototype form is given in Fig. 13.

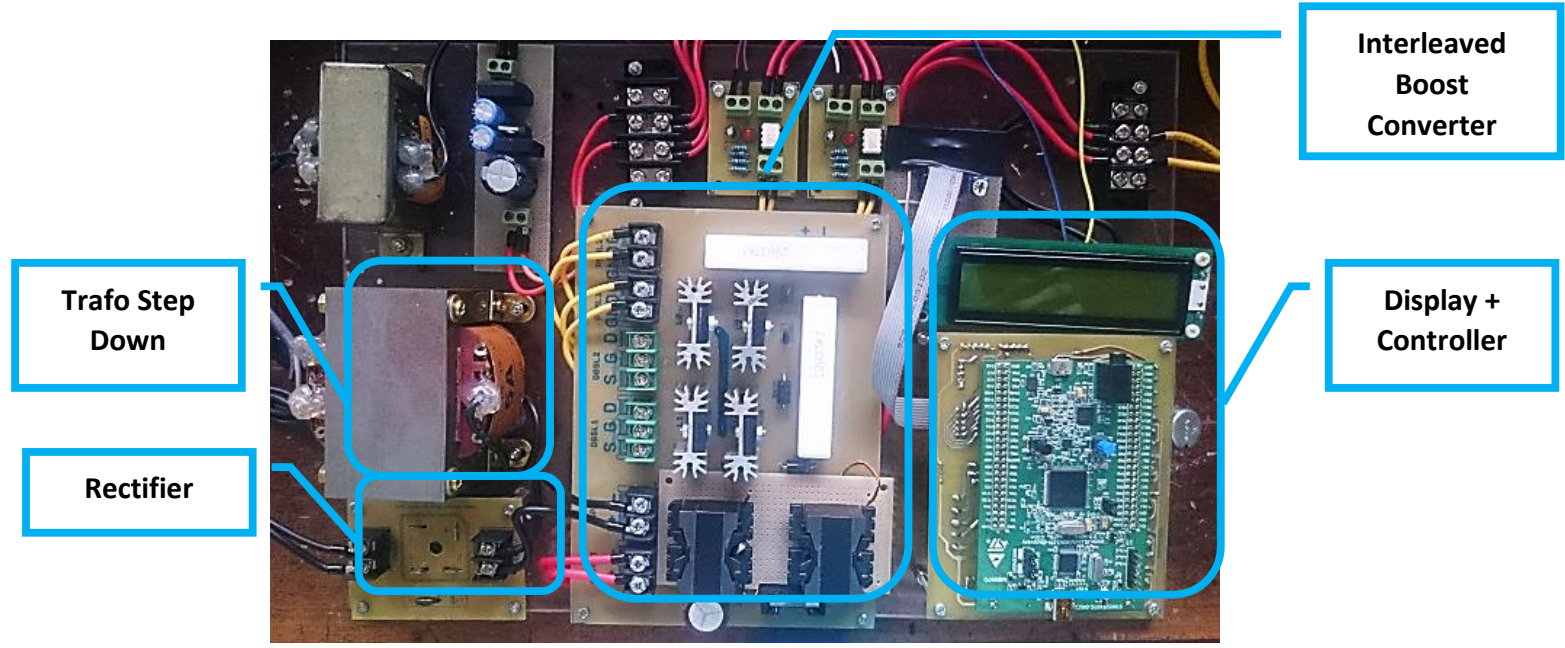

Fig. 13. Complete hardware implementation

Testing the system without IBC with the observed parameters are the input voltage and current waveform, the amount of Total Harmonic Distortion (THD), and the power factor. Total Harmonic Distortion (THD) is the whole summing of harmonic current in the system. This test uses a Fluke 43B Power Harmonic Analyzer. The test was carried out with a lamp load of 220V, 100W. The first experiment with a rectifier without filter capacitor and the second experiment with a rectifier in parallel filter capacitor. Test result data are shown in Tables 1 and 2.

For the calculation of DF (Distortion Factor) by calculating the current of each odd harmonic component. The value of DF determines the size of a distorted wave by comparing the fundamental current and the measured harmonic current. At the load of 5 parallel $220 \mathrm{~V} 100 \mathrm{~W}$ lamps, Table 3 shows the order harmonic current data. Then the DF value for the load of 5 lamps $220 \mathrm{~V} 100 \mathrm{~W}$ without IBC is as follows:

$$
D F_{5}=\frac{0.59}{\sqrt{0.59^{2}+0.5^{2}+0.33^{2}+0.16^{2}+0.04^{2}+0.03^{2}}}=0.68
$$


Table 1. The system without PFC IBC (rectifier without capacitor)

\begin{tabular}{lcccccc} 
Load & VinAC & Vout & Iout & Iin $_{A C}$ & PF & DPF \\
& (V) & (V) & (A) & (A) & & \\
\hline 5 lamps & 55.8 & 48 & 0.50 & 0.40 & 1 & 1
\end{tabular}

Table 2. The system without PFC IBC (rectifier with capacitor)

\begin{tabular}{cccccccc}
\hline \multirow{2}{*}{ Load } & VinAC & Vout & Iout & $\operatorname{Iin}_{\text {AC }}$ & & & \\
& $(\mathbf{V})$ & (V) & (A) & (A) & & & \\
\hline 5 lamps & 55.8 & 48 & 0.50 & 0.85 & 0.67 & 1 & 0.68 \\
\hline
\end{tabular}

Table 3. The harmonic current of the system without PFC IBC (rectifier with capacitor)

\begin{tabular}{ccccccc}
\hline \multirow{2}{*}{ Load } & \multicolumn{6}{c}{ Harmonic order } \\
& $\mathbf{1}$ & $\mathbf{3}$ & $\mathbf{5}$ & $\mathbf{7}$ & $\mathbf{9}$ & $\mathbf{1 1}$ \\
\hline 5 lamps & 0.59 & 0.50 & 0.33 & 0.16 & 0.04 & 0.03 \\
\hline
\end{tabular}

Next, test the system with an IBC without a large output capacitor filter. The experiments were carried out with a rectifier without a capacitor filter. Test data results are shown in Tables 4 and 5 . The power factor of the three load systems has an average of 0.91 . Based on the measured order harmonic currents as in Table 5, the DF values for loads of 3,4 and $5220 \mathrm{~V} 100 \mathrm{~W}$ lamps with IBC are as follows:

$$
\begin{aligned}
& D F_{5}=\frac{1.22}{\sqrt{1.22^{2}+0.43^{2}+0.03^{2}+0.08^{2}+0.02^{2}}}=0.94 \\
& D F_{4}=\frac{1.22}{\sqrt{1^{2}+0.42^{2}+0.04^{2}+0.07^{2}+0.02^{2}+0.01^{2}}}=0.91 \\
& D F_{3}=\frac{0.49}{\sqrt{0.49^{2}+0.29^{2}+0.16^{2}+0.07^{2}+0.02^{2}+0.03^{2}}}=0.82
\end{aligned}
$$

\begin{tabular}{|c|c|c|c|c|c|c|c|}
\hline Load & $\begin{array}{c}\mathbf{V}_{\text {inAC }} \\
(\mathrm{V})\end{array}$ & $\begin{array}{c}\text { Vout } \\
\text { (V) }\end{array}$ & $\begin{array}{l}\text { Iout } \\
\text { (A) }\end{array}$ & $\begin{array}{c}\operatorname{Iin}_{\mathrm{AC}} \\
\text { (A) }\end{array}$ & PF & DPF & DF \\
\hline 5 lamps & 20.66 & 48.1 & 0.50 & 1.30 & 0.93 & 1 & 0.94 \\
\hline 4 lamps & 20.66 & 48.1 & 0.40 & 1.09 & 0.91 & 1 & 0.91 \\
\hline 3 lamps & 20.66 & 48.1 & 0.30 & 0.61 & 0.90 & 1 & 0.82 \\
\hline
\end{tabular}

Table 4. System with PFC IBC and load variation

Table 5. The harmonic current of system with PFC IBC and load variation

\begin{tabular}{ccccccc}
\hline \multirow{2}{*}{ Load } & \multicolumn{7}{c}{ Harmonic order } \\
& $\mathbf{1}$ & $\mathbf{3}$ & $\mathbf{5}$ & $\mathbf{7}$ & $\mathbf{9}$ & $\mathbf{1 1}$ \\
\hline 5 lamps & 1.22 & 0.43 & 0.03 & 0.08 & 0.00 & 0.02 \\
4 lamps & 1.00 & 0.42 & 0.04 & 0.07 & 0.02 & 0.01 \\
3 lamps & 0.49 & 0.29 & 0.16 & 0.07 & 0.02 & 0.03 \\
\hline
\end{tabular}


System testing without Interleaved Boost Converter is carried out to know the system power factor value before power factor improvement is carried out. So that we can find out the magnitude of the power improvement using the PFC circuit. Because without the Interleaved Boost Converter (IBC) the rectifier output goes directly to the load, so it uses a 1-phase variac to adjust the 48volt output voltage. Testing the rectifier without a capacitor filter using a 220 volt 100 watt lamp load which produces a pf near unity. Fig. 14a shows the test results using 5 parallel 220 volt 100 watt lamps without IBC and a rectifier without filter capacitor. While testing the rectifier with a filter capacitor using the same load produces a pf of 0.67 which is shown in Fig. 14b.

The results of testing the system with an Interleaved Boost Converter (IBC) with a lamp load of 220 volts $100 \mathrm{~W}$ are shown in Fig. 15b. The resulting power factor is 0.93 .

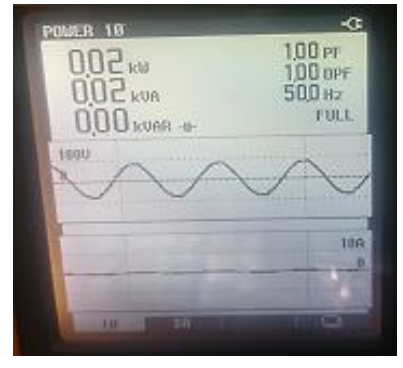

(a)

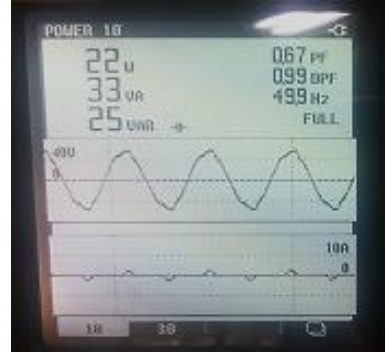

(b)

Fig. 14. Power factor system without PFC IBC (a) Rectifier without capacitor (b) Rectifier with capacitor

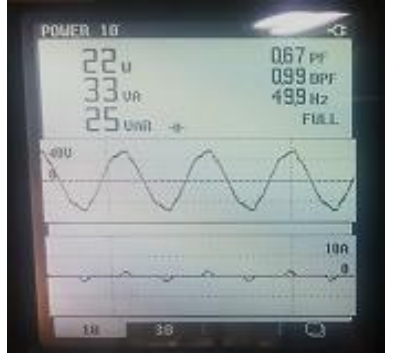

(a)

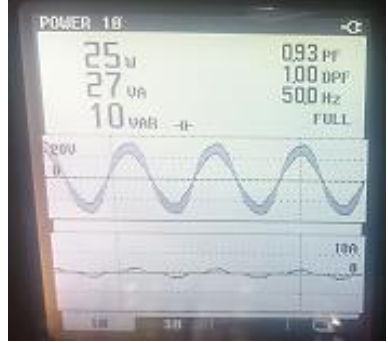

(b)

Fig. 15. Power factor system (a) without PFC IBC (b) with PFC IBC

\section{Conclusion}

The power factor improvement converter circuit using interleaved boost converter (IBC) mode has been achieved both simulation and experimentally. The proposed power factor compensation is close to unity. The simulation results that were successfully carried out in the Matlab Simulink software regarding IBC as a series of power factor improvements with fuzzy logic controllers can increase the power factor (pf) to 0.94. To evaluate the IBC design, it has been proven that the implementation of tools with various loads can achieve the best power factor improvement from 0.67 to 0.93 . The result of harmonic compensation using IBC can reduce THDi from $72.3 \%$ to $33.4 \%$. The proposed system has the potential to be applied to a larger system capacity. 


\section{References}

[1] A. Marcos-Pastor, E. Vidal-Idiarte, A. Cid-Pastor, and L. Martinez-Salamero, "Interleaved Digital Power Factor Correction Based on the Sliding-Mode Approach," IEEE Trans. Power Electron., vol. 31, no. 6, pp. 4641-4653, 2016, doi: 10.1109/TPEL.2015.2476698.

[2] E. Purwanto, F. D. Murdianto, D. W. Herlambang, G. Basuki, and M. P. Jati, "ThreePhase Direct Matrix Converter With Space Vector Modulation for Induction Motor Drive," in IEEE International Conference on Applied Information Technology and Innovation (ICAITI), 2019.

[3] M. S. Khan, S. Sathyan, H. Sugali, and S. S. C. Bommagani, "Design of On-Board Battery Charger using Interleaved Bridgeless Type PFC and Phase Shifted Full Bridge Converter," in IEEE International Students Conference on Electrical, Electronics and Computer Science, 2020, pp. 7-11.

[4] S. Musumeci, R. Bojoi, S. Borlo, and E. Armando, "IGBT based Three Channel Interleaved PFC Boost Converter for Inverter Front-End Application," in 2019 AEIT International Annual Conference (AEIT), 2019, pp. 1-6.

[5] C. Zhang et al., "WBG Partial Power Processing: A New PFC Design with Interleaved MHz-Frequency GaN and Low-Frequency Si Phases," in 2019 IEEE Energy Conversion Congress and Exposition (ECCE), 2019, pp. 2702-2706.

[6] M. Park, J. Baek, Y. Jeong, and G. Moon, “An Interleaved Totem-pole Bridgeless Boost PFC Converter with Soft-switching Capability Adopting Phase-shifting Control," IEEE Trans. Power Electron., vol. 8993, no. c, pp. 1-8, 2019, doi: 10.1109/TPEL.2019.2900342.

[7] J. Hu, W. Xiao, B. Zhang, D. Qiu, and C. N. M. Ho, "A Single Phase Hybrid Interleaved Parallel Boost PFC Converter," in 2018 IEEE Energy Conversion Congress and Exposition (ECCE), 2018, vol. 6, no. c, pp. 2855-2859.

[8] V. K. Bussa, R. K. Singh, R. Mahanty, and V. N. Lal, "Steady State Analysis of High Gain Interleaved Boost Converter at Different Operating Regions," in 2018 IEEE Industry Applications Society Annual Meeting (IAS), 2018, pp. 1-6.

[9] S. Borlo, D. Cittanti, M. Gregorio, F. Mandrile, and S. Musumeci, "Comparative CCMDCM Design Evaluation of Power Inductors in Interleaved PFC Stage for Electric Vehicle Battery Chargers," in 2019 International Conference on Clean Electrical Power (ICCEP), 2019, pp. 180-186.

[10] S. Gangavarapu and A. K. Rathore, "Analysis and Design of Three-Phase Interleaved Buck-Boost Derived PFC Converter," in 2019 IEEE Industry Applications Society Annual Meeting, 2019, pp. 1-8.

[11] K. Lee, J. Jeong, S. Hong, T. Kim, and T. Kwon, "Development of Enhanced Interleaved PFC Boost Converter typed 650V Intelligent Power Module for HVAC Systems," in PCIM Europe, 2019, no. May, pp. 7-9.

[12] R. T. Ryan, J. G. Hayes, R. Morrison, and D. Hogan, "Digital Control of an Interleaved BCM Boost PFC Converter with Fast Transient Response at Low Input Voltage,” 2017, pp. 257-264.

[13] M. O. Badawy, Y. Sozer, and J. A. De Abreu-garcia, "A Novel Control for a Cascaded Buck Boost PFC Converter Operating in Discontinuous Capacitor Voltage Mode," IEEE Trans. Ind. Electron., vol. 0046, no. c, pp. 1-12, 2016, doi: 
10.1109/TIE.2016.2539247.

[14] E. Purwanto, M. P. Jati, B. Sumantri, I. Ferdiansyah, and G. Basuki, "Optimasi Fuzzy Supervisory Control pada Performa Matrix Converter Drive 3x3 di Empat Kuadran Operasi," J. Elkomnika, vol. 9, no. 1, pp. 31-42, 2021.

[15] L. Gu, W. Liang, M. Praglin, S. Chakrabonty, and J. Rivas-davila, “A Wide-InputRange High-Efficiency Step-down Power Factor Correction Converter Using Variable Frequency Multiplier Technique," IEEE Trans. Power Electron., vol. 8993, no. c, pp. 1-12, 2018, doi: 10.1109/TPEL.2018.2796582.

[16] M. P. Jati, E. Purwanto, B. Sumantri, S. Sutedjo, and D. O. Anggriawan, "Desain dan Implementasi Interleaved Boost Converter untuk Power Factor Correction Menggunakan Pengendali Logika Fuzzy," J. Integr., vol. 12, no. 1, pp. 41-47, 2020. 